\title{
Educação Ambiental e Ensino de Ciências: Contribuições de uma Aula de CAMPo
}

\author{
ENVIRONMENTAL EDUCATION AND SCIENCE TEACHING: CONTRIBUTIONS \\ FROM A FIELD CLASS
}

DOI: http://dx.doi.org/10.23926/RPD.2526-2149.2018.v3.n2.p539-556.id235

\section{Ana Flávia Silva de \\ Assis \\ Mestre em Ensino de \\ Ciências Naturais (UFMT). anaflavia.bio@gmail.com}

\section{Débora Eriléia Pedrotti Mansilla}

Doutora em Ciências

(UFSCAR)

Professora na Universidade Federal de Mato Grosso (UFMT). deborapedrotti@gmail.com
Resumo: A Política Nacional de Educação Ambiental regulamenta a necessidade de contemplar a Educação Ambiental em todos os níveis e modalidades de ensino, sem delimitá-la como disciplina específica do currículo. A presente pesquisa teve como objetivo identificar as concepções de ambiente desenvolvidas em uma aula de campo com estudantes do ensino médio de uma Escola Estadual em Tempo Integral no município de Rondonópolis, MT. O percurso metodológico se deu através de visita prévia ao local de estudo, aplicação do questionário préaula de campo, do roteiro para roda de conversa, vivência em campo e aplicação do questionário pós-aula de campo. Os resultados do questionário inicial e da roda de conversa evidenciam que os estudantes não têm clareza do que entendem por Educação Ambiental, sendo as Concepções de Natureza e Lugar em que se vive as mais frequentes. Através dos relatos durante a aula de campo e do questionário foi possível perceber Concepções mais abrangentes sobre o ambiente se comparado aos resultados obtidos inicialmente. Pode-se concluir que durante a aula de campo, fluíram sentimentos de bem estar, amizade, solidariedade, partilha e respeito, que desencadearam em aprendizados significativos dos conceitos científicos através da vivência em ambiente natural.

Palavras-chave: Educação Ambiental. Ensino de Ciências. Aula de Campo.

\begin{abstract}
The National Environmental Education Policy regulates the need to contemplate Environmental Education at all levels and modalities of teaching, without delimiting it as a specific discipline of the curriculum. The present research had as objective to identify the conceptions of environment developed in a field class with high school students of a State School in Integral Time in the municipality of Rondonópolis, MT. The methodological course was based on a previous visit to the study site, the application of the pre-camp questionnaire, the script for the discussion wheel, the experience in the field and the application of the post-field questionnaire. The results of the initial questionnaire and the discussion wheel show that students are not clear about what they mean by Environmental Education, and the Nature and Place Concepts are the most frequent ones. Through the reports during the field class and the questionnaire it was possible to perceive more comprehensive conceptions about the environment compared to the results obtained initially. It can be concluded that during the field lesson, feelings of well-being, friendship, solidarity, sharing and respect flowed that triggered in meaningful learning of scientific concepts through living in a natural environment.
\end{abstract}

Keywords: Environmental Education. Science Teaching. Field Classroom. 


\section{INTRODUÇÃO}

Ensinar ciências de modo significativo tem sido motivo de pesquisas em educação em ciências, bem como inquietação para os professores de ciências. A dificuldade de colocar em prática os novos pressupostos, frutos de pesquisas na área de ensino de ciências, decorre tanto da própria complexidade da natureza, quanto das concepções filosóficas e crenças dos educadores sobre o caráter do conhecimento científico e o modo como os alunos aprendem (SENICIATO; CAVASSAN, 2008).

O ensino de Educação Ambiental nos espaços escolares e não escolares assume o caráter obrigatório a partir de 1999, com a Política Nacional de Educação Ambiental. Entretanto, são muitas as dificuldades docentes no que tange à ampliação da temática de forma a contribuir com a formação de indivíduos críticos, imbuídos de valores éticos em relação à vida e com conhecimentos consolidados que possam ser utilizados na intervenção social, situação essa que se encontra distante das necessidades atuais (JUNQUEIRA; OLIVEIRA, 2015).

A utilização pedagógica de espaços não formais como parques urbanos, áreas verdes remanescentes e bosques, proporcionam ao estudante a percepção de que fenômenos e processos naturais estão presentes no ambiente como um todo, não apenas no que ingenuamente é chamado de natureza (CÉSAR e CAMPOS, 2017).

As vivências em campo oportunizam ao estudante refletir suas concepções, levando-o a (re) conhecer a Educação Ambiental como uma alternativa possível para a construção de uma sociedade sustentável. Esse artigo é resultado de uma dissertação de mestrado que objetivou evidenciar as concepções de ambiente desenvolvidas em uma aula de campo por estudantes do ensino médio de uma Escola Estadual Plena no município de Rondonópolis-MT e para sustentarmos as respostas ao objetivo geral nos baseamos nos seguintes objetivos específicos: evidenciar os sentimentos que são desencadeados a partir de uma vivência em ambiente de área verde remanescente; avaliar a aula de campo como estratégia para o desenvolvimento da educação ambiental no currículo escolar e demonstrar que a aula de campo pode contribuir para a aprendizagem dos estudantes.

\section{REFERENCIAL TEÓRICO}

A Política Nacional de Educação Ambiental foi instituída pela Lei n 9.795 de 27 de Abril de 1999. No Capítulo I, o art. $1^{\circ}$ define o conceito de Educação Ambiental como processos por meio dos quais o indivíduo e a coletividade constroem valores sociais, conhecimentos, habilidades, atitudes e competências voltadas para a conservação do meio ambiente, bem de 
uso comum do povo, essencial à sadia qualidade de vida e sua sustentabilidade (BRASIL, 1999). O art. $2^{\circ}$ enfatiza a necessidade da Educação Ambiental estar presente de maneira articulada em todos os níveis e modalidades de ensino.

No Capítulo II, o art. $8^{\circ} \S 2^{\circ}$ esclarece que não há um público alvo para o desenvolvimento de práticas educativas relacionadas à educação ambiental, estas, devem ser pensadas no coletivo, por todos os envolvidos no processo educativo formal e/ou não-formal.

A Seção II, deste mesmo capítulo, prevê que o desenvolvimento da Educação Ambiental no Ensino Formal engloba a educação básica, superior, especial, profissional e de jovens e adultos no que se refere aos currículos das instituições públicas ou privadas de todo território nacional, sendo evidenciado no art. $10, \S 1^{\circ}$ que esta não deve ser implantada como disciplina específica no currículo.

O Plano Nacional de Educação (PNE) é um documento construído coletivamente que tem como objetivo principal nortear o planejamento das políticas públicas educacionais em um período de dez anos. A Meta 06 do PNE, Lei n n $^{\circ} 13.005$ de 25 de junho de 2014 prevê: "Oferecer educação em tempo integral em, no mínimo, cinquenta por cento das escolas públicas, de forma a atender, pelo menos, vinte e cinco por cento dos(as) alunos(as) da educação básica" (BRASIL, 2014, p.33).

O Estado de Mato Grosso por meio da Assembleia Legislativa publicou a Lei ${ }^{\circ} 10.111$ de 06 de junho de 2014, que se refere ao Plano Estadual de Educação, cujas metas passaram a vigorar a partir da data de sua publicação.

Ao debruçar-se nos documentos, analisando as metas e estratégias de ambos, é perceptível que há um alinhamento entre os Planos Nacional e o Estadual de Educação. No que diz respeito às escolas em Tempo Integral, o Plano Estadual propôs a meta 16 que prevê: "Aumentar progressivamente a carga horária em 01 hora por ano, atingindo pelo menos sete horas diárias, para $25 \%$ (vinte e cinco por cento) dos estudantes matriculados na educação básica até 2017" (MATO GROSSO, 2014, p.39).

No ano de 2017, houve a adesão do Programa de Implementação de Educação em Tempo Integral instituído pelo Ministério da Educação (MEC), através da portaria no 1.145 de 10 de outubro de 2016, em conformidade com a medida provisória n ${ }^{\circ} 746$ de 22 de janeiro de 2016, nomeada Escola Plena. Diante desse contexto, a escolar foi uma das 14 unidades escolares contempladas pelo "Projeto Escola Plena" e começou a ofertar Ensino Médio em Tempo Integral a partir de 2017. 
Anastasiou e Alves (2004) na obra "Processos de Ensinagem na Universidade: pressupostos para as estratégias de trabalho em aula" apresentam a necessidade do docente em se apropriar de novas formas de ensinar que propiciem a aprendizagem, esforçando-se a superar a tendência tecnicista e caminhar ao desenvolvimento do processo dialético do trabalho.

O verbo ensinar, do latim insignare, significa marcar com um sinal, que deveria ser de vida, busca e despertar para o conhecimento (ANASTASIOU, 2004, p. 13). Neste sentido, o professor deve refletir se a forma como ensina, de fato desperta o estudante para o conhecimento ou, se apenas o transmite informações acadêmicas. Para Anastasiou (2004), o aprender por sua vez está ligado muito mais à retenção do conhecimento na memória mediante estudo do que a apropriação do conhecimento. A autora afirma que é preciso ir além do aprender, é preciso apreender. $\mathrm{O}$ apreender, do latim apprehendere, significa segurar, prender, pegar, assimilar mentalmente, entender, compreender, agarrar. Não se trata de um verbo passivo; para apreender é preciso agir, exercitar-se, informar-se, tomar para si, apropriar-se, entre outros fatores. (ANASTASIOU, 2004, p. 14).

Aprofundando no conceito de apreender, Anastasiou (2004) propõe a necessidade de se revisar os termos assistir ou dar aulas. Para a autora, os termos precisam ser substituídos por fazer aulas.

ORÓ (1999) por sua vez, aprofunda a discussão sobre os conteúdos procedimentais na área do Meio Natural. O autor aborda as inúmeras dificuldades para que a aprendizagem das Ciências Naturais aconteça e destaca que, dedicar-se aos fatos e conceitos, seguindo o plano de ensino proposto é muito mais confortável para o professor. Para ele, a ciência e a técnica ainda são exploradas na escola como dois aspectos distintos, embora seja sabido serem pertencentes à mesma realidade.

Essa dicotomia ente teoria e prática está muito presente em nossa sociedade e, em especial, na aprendizagem científica, tem consequências importantes na prática educativa: o processo de aprendizagem científica costuma reduzir-se a uma acumulação de conteúdos conceituais, deixando de lado os aspectos técnicos e os aplicados (ORÓ, 1999, p. 22).

Oró (1999) comenta que por mais bem elaboradas que as produções humanas sejam, é preciso ter contato com a realidade, uma vez que a aprendizagem não deve ficar estritamente no enfoque conceitual. Complementa que a escola deve levar em consideração o desenvolvimento dos conhecimentos conceituais e procedimentais ao mesmo tempo, caso contrário, perde grande parte de seu significado como instituição educacional. 
companheiros ou com os professores, comparar fatos semelhantes, acompanhar um processo desde o princípio até o final, etc. o contato com a realidade é fundamental para aprender Ciências Naturais (ORÓ, 1999, p. 22).

A construção de conceitos é fortalecida quando há a relação entre teoria e prática, sem a fragmentação do conhecimento. Proporcionar a vivência ao estudante é potencializar o apreender.

Se não têm contato com a realidade, não poderão construir os conceitos, e, se baseamos a didática em um enfoque abstrato, possivelmente conseguiremos a desmotivação em determinada área do conhecimento potencialmente muito atrativa nessa etapa da educação (ORÓ, 1999, p. 22).

Muitas vezes a desmotivação do estudante é decorrente a desmotivação do próprio professor. São inúmeros os entraves da profissão e infelizmente é comum encontrarmos profissionais em exaustão decorrente as pesadas jornadas de trabalho que não tem tempo para participar de eventos científicos e educacionais (congressos, seminários, simpósios, colóquios e afins). Propõe-se o fortalecimento da formação continuada nas unidades escolares, importante para os aprofundamentos teóricos, trocas de experiências e vivências no coletivo onde os profissionais se motivam, cooperam, apoiam e auxiliam uns aos outros.

Sauvé (2005) em sua obra intitulada como "Educação Ambiental: possibilidades e limitações" aborda o meio ambiente não apenas como uma temática ou objeto de estudo, mas, como a trama da própria vida. Para a autora, é na vida que natureza e cultura se encontram e assim construímos nossa identidade e as relações entre as pessoas.

Atualmente é possível encontrar um repertório de obras que coexistem e tratam das discussões sobre Educação Ambiental e a construção de identidade do ser humano de forma ampla. Com tamanha vastidão de referenciais teóricos, a presente pesquisa restringe-se as concepções de ambiente propostas por Sauvé (2005), que categoriza em: Concepção de Ambiente como Natureza, Recurso, Problema, Sistema, Lugar em que se vive, Biosfera e Projeto Comunitário.

\section{Metodologia}

Aula de Campo foi realizada com doze $(\mathrm{N}=12)$ estudantes do Ensino Médio de uma Escola Estadual Plena do município de Rondonópolis/MT, no ano de 2017.

A pesquisa é qualitativa cujo percurso metodológico foi dividido nas seguintes etapas: 1) Visita prévia ao local de estudo; 2) Elaboração dos instrumentos de coleta e roteiro de campo; 3) Aplicação do questionário pré-aula de campo; 4) Aplicação do roteiro da roda de conversa; 
5) Vivência no campo com experimentação do roteiro de campo; 6) Aplicação do questionário pós-aula de campo.

A área de estudo é uma Zona de Unidade de Conservação (ZUC) do município de Rondonópolis/MT intitulada como Bosque Izabel Dias Goulart, conforme artigo 127 da Lei Complementar $\mathrm{N}^{\circ}$ 043, de 28 de Dezembro de 2006. A pesquisadora realizou visitas prévias ao local de estudo a fim de identificar organismos focos para compor o roteiro de campo. Nesta etapa foram plotadas as estações de paradas com auxílio do GPS.

Após a etapa de ambientação, a pesquisadora iniciou a elaboração dos instrumentos de coleta, sendo construídos dois questionários semiestruturados, o pré-aula de campo e pós-aula de campo, o roteiro para roda de conversa com os estudantes e, o roteiro de campo com as dezesseis estações de parada.

Antecedentes a ida a campo, foram realizadas três reuniões de alinhamento com os estudantes e uma reunião com os professores colaboradores para validação dos instrumentos de coletas e roteiro de aula de campo. Na primeira reunião a pesquisadora deu boas-vindas aos estudantes, explicou em linhas gerais os objetivos da pesquisa, evidenciando que a participação é voluntária. A segunda reunião teve como objetivo esclarecer a importância das documentações como termo de consentimento livre e esclarecido e autorização para uso de imagem e depoimento. A terceira reunião constituiu na aplicação do questionário pré-aula de campo e em orientações aos estudantes quanto aos materiais, procedimentos e vestimentas adequadas para aula de campo.

Durante a vivência em campo, experimentou-se o roteiro, composto por 16 (dezesseis) estações de parada. A cada estação foram feitas as considerações do roteiro. Neste momento os estudantes puderam ouvir, perguntar, trocar informações entre si, e complementar com informações adicionais. Os momentos de paradas foram descontraídos e muito produtivos. Os professores colaboradores coletaram os comentários e posturas nos cadernos de campo que posteriormente foram transcritos pela pesquisadora. Durante a aula, os estudantes ficaram livres para fotografar, filmar e anotar em todas as estações de paradas.

No retorno do campo, foram convidados a responder o questionário pós-aula de campo.

\section{Resultados}

Os resultados serão apresentados seguindo a sequência em que foram coletados.

\subsection{DADOS DO QUESTIONÁRIO PRÉ-AULA DE CAMPO}


Quando perguntados sobre a participação em aulas de campo durante a vida escolar, $75 \%$ dos estudantes $(\mathrm{N}=09)$ afirmaram ter participado de aulas de campo no ensino fundamental e médio e $25 \%(\mathrm{~N}=03)$ participaram apenas no ensino médio.

Um total de 91,6\% dos estudantes ( $\mathrm{N}=11)$ afirmaram que as aulas de campo na qual participaram tinham relação com os conteúdos trabalhados em sala pelo professor, apenas um estudante $(\mathrm{N}=01)$ relatou que a aula de campo não teve relação direta com os conteúdos aprendidos em sala.

Em relação à disciplina que mais proporcionou aulas de campo aos estudantes, foram citadas sete $(\mathrm{N}=07)$ para Ciências e Geografia, seis $(\mathrm{N}=06)$ citações para Biologia e Educação Física, seguido de Arte com cinco citações ( $\mathrm{N}=05)$. As disciplinas de Matemática, Química, Física e Inglês tiveram apenas uma citação cada ( $\mathrm{N}=01)$.

No entendimento sobre a aula de campo, os resultados apontam que metade dos estudantes participantes da pesquisa $(\mathrm{N}=06)$ entende que aula de campo se dá por meio de atividade realizadas fora da sala de aula, podendo ser realizada até no pátio da escola. Quatro estudantes ( $\mathrm{N}=04)$ consideram aula de campo como atividades desenvolvidas fora da escola, independentemente do local e, dois estudantes $(\mathrm{N}=02)$ entendem aula de campo como visita/vivência em ambientes naturais, não considerando os outros locais.

\subsection{DADOS DA RODA DE CONVERSA}

A roda de conversa foi composta por sete questões norteadoras e uma sequência de questões reflexivas. A conversa foi conduzida de maneira bastante descontraída onde os estudantes participaram ativamente. Quando perguntados se gostam de aula de campo, as respostas afirmativas foram unânimes. Demonstraram bastante empolgação com a realização da aula. Alguns relataram ter participado de várias aulas de campo, outros participaram menos, mas todos disseram ter participado em algum momento da vida acadêmica.

A compreensão do que vem a ser aula de campo estava bastante clara para alguns; outros acreditavam que a aula de campo só acontece em ambientes naturais. A confusão se dá supostamente pelo termo "campo" que remete a natureza.

Quando questionados sobre aulas em ambientes naturais, identificou-se uma tendência naturalista de alguns sentimentos, tais como: "me sinto em paz", "fico de bem consigo mesmo", "sinto ar puro, é como se limpasse meus pulmões".

A pergunta referente ao entendimento sobre Educação Ambiental revelou que os estudantes não tinham clareza de sua própria compreensão. Quando a pesquisadora os instigou 
com as perguntas reflexivas, estes mudaram o discurso várias vezes durante a conversa. Vale ressaltar que os estudantes demonstraram rejeição quando os questionamentos pautavam as concepções de "Sistema", "Projeto comunitário", "Problema" e "Biosfera", sendo mais aceitas as concepções de "Natureza" e "Lugar em que se vive", respectivamente. Através da roda de conversa foi possível identificar alguns aspectos da percepção dos estudantes e abrir as possibilidades de reflexão com a sequência de perguntas reflexivas.

\subsection{DADOS DA VIVÊNCIA EM CAMPO}

Os dados relacionados a vivência em campo estão compilados em formato de tabela onde são apresentadas a estação de parada, a descrição conforme o roteiro para aula de campo e alguns relatos da caderneta de campo de todas as paradas.

\begin{tabular}{|c|c|c|}
\hline Estação de parada & Descrição da Estação & Relatos da Caderneta de Campo \\
\hline $\begin{array}{c}1^{\mathrm{a}} \text { Estação } \\
\text { Orientações iniciais }\end{array}$ & $\begin{array}{l}\text { A primeira estação foi na entrada do } \\
\text { Bosque onde os estudantes receberam as } \\
\text { primeiras orientações sobre como } \\
\text { proceder durante as trilhas, os cuidados } \\
\text { necessários e a importância do silêncio } \\
\text { para facilitar a visualização, ouvir a } \\
\text { vocalização dos animais, a explicação da } \\
\text { pesquisadora e para que a pudessem } \\
\text { ouvir os questionamentos, comentários e } \\
\text { curiosidades dos colegas nos momentos } \\
\text { das paradas. }\end{array}$ & $\begin{array}{l}\text { "Viu, não é pra ficar conversando" } \\
\text { "Eu vou andar na trilha, tenho } \\
\text { medo de bicho" } \\
\text { "Se fizer muito barulho os animais } \\
\text { se escondem" } \\
\text { "Estou ansiosa pra começar" } \\
\text { "Vou tirar várias fotos" }\end{array}$ \\
\hline $\begin{array}{c}2^{\text {a }} \text { Estação } \\
\text { Histórico do Bosque } \\
\text { e Espaço de } \\
\text { Convivência }\end{array}$ & $\begin{array}{l}\text { Nesta estação a pesquisadora relata o } \\
\text { histórico do Bosque Izabel Dias Goulart. } \\
\text { Explica aos estudantes que apesar do } \\
\text { local ser popularmente conhecido como } \\
\text { Horto Florestal, trata-se de uma Zona de } \\
\text { Unidade de Conservação (ZUC), uma } \\
\text { área verde intitulada como Bosque do } \\
\text { município de Rondonópolis, destinado à } \\
\text { proteção de recursos naturais com } \\
\text { predominância de uso público ou de } \\
\text { lazer. Os estudantes foram convidados a } \\
\text { observar o local em todos os seus } \\
\text { aspectos. A entrada do bosque é } \\
\text { destinada a convivência, possui mesas, } \\
\text { bancos, parque para as crianças, } \\
\text { banheiros, bebedouro, lixeiras seletivas e } \\
\text { espaço para realização de piqueniques. }\end{array}$ & $\begin{array}{l}\text { - "Sempre achei que aqui chamava } \\
\text { horto" } \\
\text { - "Horto é ali do lado, aqui é } \\
\text { bosque" } \\
\text { - "Vou contar essa pra minha mãe, } \\
\text { ela fala que aqui é horto" } \\
\text { "Se é bosque municipal, então é a } \\
\text { prefeitura que cuida daqui" } \\
\text { "Nunca tinha vindo aqui, é bonito" } \\
\text { "Sempre venho aqui pra caminhar } \\
\text { fim de semana" } \\
\text { "Minha mãe vem trazer minha irmã } \\
\text { pra brincar porque é tranquilo, as } \\
\text { vezes eu venho também". } \\
\text { "Aqui tem bastante banco, dá pra } \\
\text { sentar e bater papo" }\end{array}$ \\
\hline $3^{\text {a }}$ Estação & $\begin{array}{l}\text { A pesquisadora chamou a atenção dos } \\
\text { estudantes para que observassem os }\end{array}$ & “Nossa! quanto gato!". \\
\hline
\end{tabular}




\begin{tabular}{|c|c|c|}
\hline $\begin{array}{c}\text { Espécies } \\
\text { invasoras/exóticas }\end{array}$ & $\begin{array}{l}\text { jabutis e a quantidade de gatos no local, } \\
\text { alguns adultos e outros ainda filhotes, } \\
\text { possivelmente oriundos de abandono. A } \\
\text { terceira parada também é marcada pela } \\
\text { observação de plantas ornamentais e uma } \\
\text { bromeliaceae popularmente conhecida } \\
\text { como gravatá, que está se alastrando por } \\
\text { todo o bosque. Neste momento são } \\
\text { explicados conceitos como espécies } \\
\text { exóticas, controle biológico de pragas, } \\
\text { cadeia alimentar. }\end{array}$ & 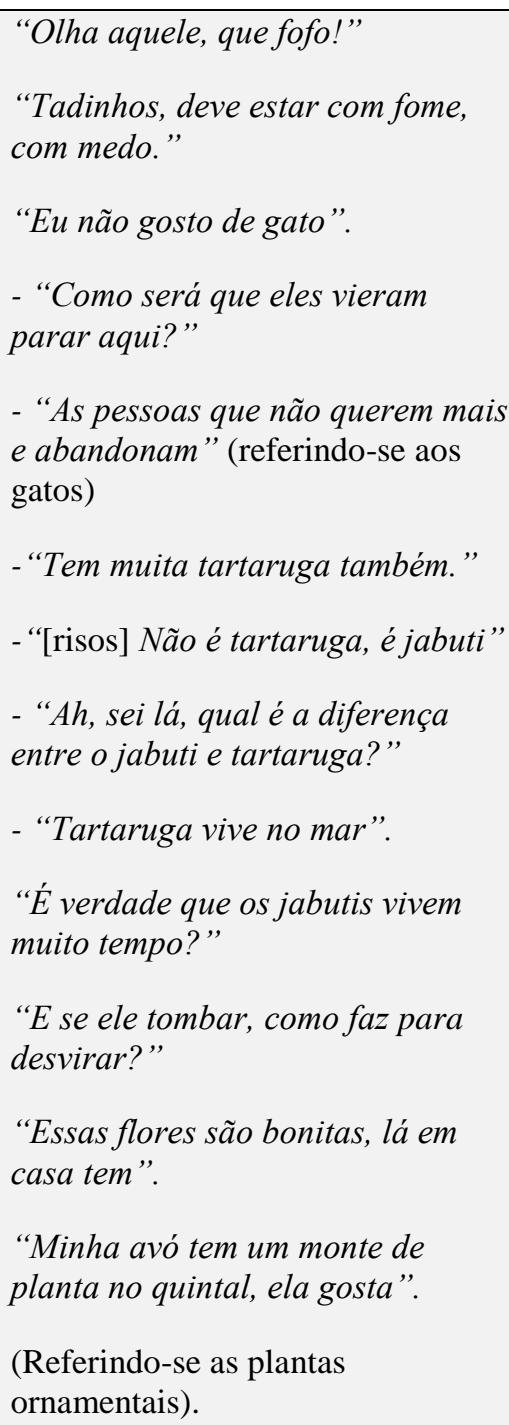 \\
\hline $\begin{array}{c}4^{\mathrm{a}} \text { Estação } \\
\text { Sensação térmica }\end{array}$ & $\begin{array}{l}\text { A quarta estação está no início da trilha, } \\
\text { onde é perceptível a mudança na } \\
\text { sensação térmica. São discutidos } \\
\text { conceitos de fotossíntese, transpiração } \\
\text { vegetal e abertura e fechamento dos } \\
\text { estômatos. Os estudantes são instigados a } \\
\text { observarem a copa das árvores e } \\
\text { perceberem os diversos estratos na } \\
\text { vegetação, identificando arbustos e } \\
\text { árvores de pequeno, médio e grande } \\
\text { porte. }\end{array}$ & $\begin{array}{l}\text { - “Aqui é mais fresquinho”. } \\
\text { - "Também achei”. } \\
\text { - "É por causa da transpiração das } \\
\text { árvores" } \\
\text { "Parece que é mais úmido”. } \\
\text { "Eu já estou suando”. } \\
\text { "É fresco e ao mesmo tempo } \\
\text { quente” }\end{array}$ \\
\hline $\begin{array}{c}\mathbf{5}^{\mathbf{a}} \text { Estação } \\
\text { Placas } \\
\text { identificadoras }\end{array}$ & $\begin{array}{l}\text { A pesquisadora mostra aos estudantes } \\
\text { uma placa de identificação de uma } \\
\text { árvore, com nome popular e nome } \\
\text { científico. Neste momento faz uma } \\
\text { abordagem sobre a importância do nome } \\
\text { científico das espécies e discute } \\
\text { superficialmente as técnicas mais } \\
\text { recentes utilizadas na classificação }\end{array}$ & $\begin{array}{l}\text { "Ah, que legal” } \\
\text { "Eu já vim aqui várias vezes e } \\
\text { nunca reparei essa placa” } \\
\text { "O povo estraga tudo! Que raiva } \\
\text { que me dá!” (referindo-se a placa } \\
\text { que está danificada) }\end{array}$ \\
\hline
\end{tabular}




\begin{tabular}{|c|c|c|}
\hline & $\begin{array}{l}\text { taxonômica. A pesquisadora chama a } \\
\text { atenção dos estudantes para as poucas } \\
\text { placas de identificação das espécies no } \\
\text { decorrer da trilha. }\end{array}$ & $\begin{array}{l}\text { "Virola, parece vitrola" } \\
\text { "Nome cientifico é sempre } \\
\text { complicado" } \\
\text { "Acho que o nome cientifico é tipo } \\
\text { o RG da planta". }\end{array}$ \\
\hline $\begin{array}{l}6^{\text {a }} \text { Estação } \\
\text { Aguçando os } \\
\text { sentidos }\end{array}$ & $\begin{array}{l}\text { Os estudantes são convidados a ficar em } \\
\text { silêncio, fecharem os olhos e deixar que } \\
\text { os sentidos captem a mata ao redor, os } \\
\text { sons, cheiros, as vibrações, a sensação } \\
\text { térmica. Em seguida são convidados a } \\
\text { abrirem os olhos e realizarem a } \\
\text { contemplação do local. }\end{array}$ & $\begin{array}{l}\text { - "Tá ouvindo isso, é o canto de um } \\
\text { pássaro bem baixinho" } \\
\text { - “Eu só tô ouvindo mosquito } \\
\text { rondando meu ouvido [risos]" } \\
\text { "O cheiro é diferente", } \\
\text { "É muito gostoso ouvir o canto dos } \\
\text { pássaros" } \\
\text { "Me dá muita paz" } \\
\text { "Eu também acho que dá paz, } \\
\text { relaxa a gente”" }\end{array}$ \\
\hline $\begin{array}{l}7^{\text {a }} \text { Estação } \\
\text { Briófitas }\end{array}$ & $\begin{array}{l}\text { Neste ponto, a trilha está repleta de } \\
\text { briófitas, formando um "tapete verde". A } \\
\text { pesquisadora convida os estudantes a } \\
\text { tocar e observar de perto para que } \\
\text { identifiquem as estruturas reprodutivas. } \\
\text { Neste momento são feitas as explicações } \\
\text { sobre os aspectos evolutivos, as } \\
\text { características gerais e o ciclo } \\
\text { reprodutivo. }\end{array}$ & $\begin{array}{l}\text { "São plantas miniaturas" } \\
\text { "Isso é lodo?" } \\
\text { "No muro de casa sempre aparece } \\
\text { quando é época de chuva" } \\
\text { "Olha que linda!" } \\
\text { "Olha bem de perto que você vai } \\
\text { ver o cabinho que ela ta falando", } \\
\text { (referindo-se a explicação da } \\
\text { pesquisadora) } \\
\text { "Forma um tapete verde no chão", }\end{array}$ \\
\hline $\begin{array}{c}8^{\mathbf{a}} \text { Estação } \\
\text { Serrapilheira }\end{array}$ & $\begin{array}{l}\text { O acúmulo de material orgânico é mais } \\
\text { evidente neste ponto da trilha. A } \\
\text { pesquisadora relatou a importância da } \\
\text { decomposição e da ciclagem dos } \\
\text { nutrientes no solo. Fez um comparativo } \\
\text { demonstrando aos estudantes as } \\
\text { diferenças entre uma folha recém caída } \\
\text { da árvore com as em estado de } \\
\text { decomposição. }\end{array}$ & $\begin{array}{l}\text { "Serrapilheira... nome dado a um } \\
\text { amontoado de folhas no chão" } \\
\text { [risos] } \\
\text { "Aqui em baixo é úmido, as folhas } \\
\text { estão molhadas" } \\
\text { "Olha a diferença das folhas", } \\
\text { (referindo-se a demonstração de } \\
\text { uma folha recém caída com outras } \\
\text { em decomposição) } \\
\text { "Tem um gato deitado em cima da } \\
\text { Serrapilheira”" } \\
\text { "Mas se essas plantas não são } \\
\text { daqui, como estão aqui? Alguém } \\
\text { plantou?" }\end{array}$ \\
\hline
\end{tabular}




\begin{tabular}{|c|c|c|}
\hline & & $\begin{array}{l}\text { "Elas parecem abacaxi!” } \\
\text { "Parece uma bromélia que minha } \\
\text { mãe tem” (referindo-se a } \\
\text { bromeliaceae no interior da trilha) } \\
\text { - “Algumas tem flor e outras não.” } \\
\text { - “Cadê a flor? Não estou vendo.” } \\
\text { - “Ali, essa vermelha.” } \\
\text { - “Ah, isso é a flor? Achei que era } \\
\text { tipo um abacaxi [risos]” } \\
\text { (referindo-se a bromeliaceae no } \\
\text { interior da trilha) }\end{array}$ \\
\hline $\begin{array}{c}9^{a} \text { Estação } \\
\text { Árvores para o } \\
\text { toque }\end{array}$ & $\begin{array}{l}\text { Este momento foi marcado pelo tato. Os } \\
\text { estudantes foram convidados a sentir a } \\
\text { casca de várias árvores e descrever suas } \\
\text { percepções. A pesquisadora explicou } \\
\text { sobre as diferentes texturas dos caules } \\
\text { das árvores e a relação com a defesa } \\
\text { contra insetos e perda de água. }\end{array}$ & $\begin{array}{l}\text { "Tem umas cascas bem grossas” } \\
\text { - “Ai! Passa a mão nesse, me sinto } \\
\text { passando a mão em um } \\
\text { dinossauro” } \\
\text { - “[risos] você já passou a mão em } \\
\text { dinossauro por acaso? } \\
\text { - “[risos] não né, mas imagino que } \\
\text { seja tipo assim” } \\
\text { "Esse tronco é mais liso que } \\
\text { aquele”" } \\
\text { "Aquele lá está cheio de cupim” }\end{array}$ \\
\hline $\begin{array}{c}\text { 10 } \\
\text { Epstaçãfita }\end{array}$ & $\begin{array}{l}\text { A pesquisadora explica que as plantas } \\
\text { epífitas são conhecidas por utilizar outra } \\
\text { planta como substrato para fixação, mas, } \\
\text { não causam mal, pois não retiram } \\
\text { nutrientes da planta que lhe fornece } \\
\text { suporte. As angiospermas mais comuns } \\
\text { são das famílias Bromeliaceae } \\
\text { (bromélias) e Orchidaceae (orquídeas) e } \\
\text { das pteridófitas, as samambaias são as } \\
\text { mais comuns. Explica ainda que as } \\
\text { epífitas possuem adaptações específicas, } \\
\text { como as raízes aéreas. A pesquisadora } \\
\text { retoma com os estudantes as principais } \\
\text { características dos grupos: briófitas, } \\
\text { pteridófitas, gimnospermase } \\
\text { angiospermas. }\end{array}$ & $\begin{array}{l}\text { "Caraca, como aquela planta foi } \\
\text { parar lá?" } \\
\text { "Que louco mano, olha lá onde } \\
\text { estão aquelas plantas" } \\
\text { "Uma planta que nasceu em cima } \\
\text { da outra" } \\
\text { "Se não falassem eu nem ia ver, } \\
\text { fica no alto, nem estava olhando } \\
\text { pra cima" } \\
\text { "Silêncio! vocês conversam demais, } \\
\text { com esse barulho não vamos ver } \\
\text { nada" (referindo-se aos barulhos } \\
\text { das conversas dos colegas). }\end{array}$ \\
\hline $\begin{array}{c}\text { 11ª Estação } \\
\text { Grande árvore }\end{array}$ & $\begin{array}{l}\text { Nesta parada foi realizada a } \\
\text { contemplação de uma grande árvore no } \\
\text { meio da trilha. Também foram apontadas } \\
\text { as briófitas em estágio reprodutivo no } \\
\text { tronco da árvore. A pesquisadora } \\
\text { comenta sobre a exploração ilegal de } \\
\text { madeira que costumam ser com as } \\
\text { grandes árvores e complementa dizendo }\end{array}$ & $\begin{array}{l}\text { "Essa é linda!” } \\
\text { “Junta todo mundo ai, vamos tirar } \\
\text { uma foto" } \\
\text { "Essa deve custar caro, olha a } \\
\text { grossura dela" (referindo-se a }\end{array}$ \\
\hline
\end{tabular}




\begin{tabular}{|c|c|c|}
\hline & $\begin{array}{l}\text { os impactos ambientais da exploração } \\
\text { ilegal. }\end{array}$ & $\begin{array}{l}\text { explicação da pesquisadora sobre a } \\
\text { exploração de madeira ilegal) } \\
\text { "Ela está cheia de briófitas" } \\
\text { "E estão em fase de reprodução" }\end{array}$ \\
\hline $\begin{array}{c}12^{\mathrm{a}} \text { Estação } \\
\text { Estrangulamento } \\
\text { por lianas }\end{array}$ & $\begin{array}{l}\text { A pesquisadora relata aos estudantes que } \\
\text { as lianas (conhecida como cipós) podem } \\
\text { afetar o crescimento e a arquitetura da } \\
\text { árvore, uma vez que, elas podem } \\
\text { lignificar no tronco, além disso, podem } \\
\text { provocar a quebra de galhos finos. A } \\
\text { pesquisadora explica que na biologia, a } \\
\text { área de botânica e ecologia estuda a } \\
\text { relação entre as plantas terrestres e as } \\
\text { trepadeiras. }\end{array}$ & $\begin{array}{l}\text { "No sitio do meu vô ele cortava } \\
\text { tudo esses cipós" } \\
\text { "Ele mata as árvores" } \\
\text { "Olha lá, enforcou a árvore, } \\
\text { coitada!" } \\
\text { "Tem trepadeira que não mata, } \\
\text { você não está ouvindo ela falar? } \\
\text { (referindo-se a explicação). }\end{array}$ \\
\hline $\begin{array}{c}13^{\mathrm{a}} \text { Estação } \\
\text { Líquens e fungos }\end{array}$ & $\begin{array}{l}\text { Esta estação é marcada por dois } \\
\text { organismos focos. A pesquisadora } \\
\text { explica aos estudantes que liquens é a } \\
\text { associação mutualística entre algas e } \\
\text { fungos e sua presença é bioindicadora da } \\
\text { qualidade do ar. Há também a presença } \\
\text { do fungo conhecido como orelha de pau } \\
\text { e explica que o nome popular é por conta } \\
\text { de sua característica. }\end{array}$ & $\begin{array}{l}\text { "Nossa, achava que essas coisas } \\
\text { eram manchas da árvore” } \\
\text { "As briófitas são mais bonitas que } \\
\text { os liquens" } \\
\text { "Esse fungo é comestivel?" } \\
\text { - "No restaurante japonês vende um } \\
\text { monte de fungo diferente com nome } \\
\text { estranho" } \\
\text { - "Você já comeu?" } \\
\text { - "já, parece tipo um isopor". } \\
\text { "Tem chá de alguns cogumelos que } \\
\text { deixa doidão”" }\end{array}$ \\
\hline $\begin{array}{c}14^{\text {a }} \text { Estação } \\
\text { Estímulos externos }\end{array}$ & $\begin{array}{l}\text { Mimosa pudica, também conhecida } \\
\text { como dorme-dorme ou dormideira. A } \\
\text { pesquisadora esclarece a diferença entre } \\
\text { folha e folíolo, apontando aos estudantes } \\
\text { a estrutura foliar, continua explicando } \\
\text { que o fechamento das folhas se dá de } \\
\text { forma natural, como sistema de defesa } \\
\text { contra predadores. As folhas se fecham } \\
\text { porque ao receber um estímulo externo } \\
\text { ocorre a saída de água da base do folíolo, } \\
\text { ocasionando seu fechamento. A } \\
\text { pesquisadora esclarece ainda que o } \\
\text { fechamento é temporário; em minutos, a } \\
\text { água retorna a seu lugar de origem e as } \\
\text { folhas abrem novamente. }\end{array}$ & $\begin{array}{l}\text { "Acho muito dá hora essa planta" } \\
\text { "Ela é esperta, fecha rapidão } \\
\text { achando que é predador" } \\
\text { - "É verdade, a folha é composta de } \\
\text { um monte de foliolos" } \\
\text { - "Eu não sabia que tinha } \\
\text { diferença" } \\
\text { - "Nem eu [risos]" } \\
\text { "Essa é a dorme-dorme", } \\
\text { "Meu pai chama de dormideira", }\end{array}$ \\
\hline $\begin{array}{l}15^{\mathrm{a}} \text { Estação } \\
\text { Cupinzeiro }\end{array}$ & $\begin{array}{l}\text { A pesquisadora explica que quanto ao } \\
\text { comportamento, existem três principais } \\
\text { grupos de cupins. O cupim de madeira } \\
\text { seca que ataca madeira com baixo teor de } \\
\text { umidade, os cupins de madeira úmida } \\
\text { que preferem as árvores em alto teor de }\end{array}$ & $\begin{array}{l}\text { "Olha o tamanho desse cupinzeiro" } \\
\text { "Tem um buraco de tatu nele", } \\
\text { "Parece buraco de cobra", }\end{array}$ \\
\hline
\end{tabular}




\begin{tabular}{|c|c|c|}
\hline & $\begin{array}{l}\text { umidade, árvores já apodrecidas, porém } \\
\text { em bom estado e o grupo dos cupins } \\
\text { subterrâneos que se proliferam aterrados } \\
\text { no solo, ou parcialmente, elevando-se } \\
\text { acima do solo. E demonstra que o } \\
\text { grande cupinzeiro é do tipo subterrâneo } \\
\text { parcial. }\end{array}$ & $\begin{array}{l}\text { "Cupim pica duro, já levei uma } \\
\text { picada uma vez" }\end{array}$ \\
\hline $\begin{array}{l}16^{\text {a }} \text { Estação } \\
\text { Piquenique }\end{array}$ & $\begin{array}{l}\text { A última parada foi destinada ao } \\
\text { piquenique. Os estudantes puderam } \\
\text { partilhar os lanches e curtir o momento } \\
\text { em coletivo. Após, todos recolheram o } \\
\text { lixo e jogaram nas cestas seletivas. Ao } \\
\text { fim, a pesquisadora agradeceu } \\
\text { profundamente a participação e } \\
\text { colaboração de todos. }\end{array}$ & 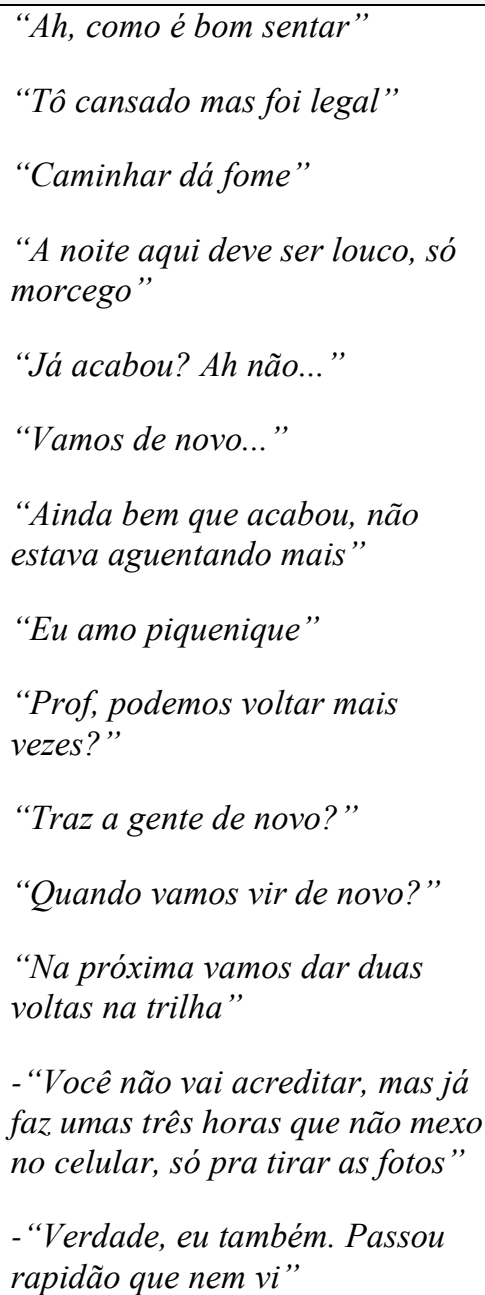 \\
\hline
\end{tabular}

Fonte: Da pesquisa, 2017.

Alguns recortes das falas dos estudantes demonstram aspectos sentimentais relacionados ao ambiente em si, "Aqui é mais fresquinho", "Aqui tem bastante banco, dá pra sentar e bater papo", "Me dá muita paz". A pesquisa de Barros et al. (2010) buscou identificar o sentimento dos visitantes do Parque Mãe Bonifácia, Cuiabá, MT. Os resultados apontam que boa parte dos entrevistados também têm percepções relacionadas ao bem estar anímico e bem estar clínico.

Os estudos de percepção constituem uma visão ímpar, uma vez que, a investigação e compreensão dos sentimentos e valores têm um papel importante para formação de juízos de valor e atitudes que orientam ações sobre estes espaços (COSTA E COLESANTI, 2011). 
A sexta estação de parada foi marcada pelas sensações, "O cheiro é diferente", "É muito gostoso ouvir o canto dos pássaros", "Eu também acho que dá paz, relaxa a gente”. Os aspectos ligados aos sentidos, ao grupo e ao indivíduo e o meio ambiente interagem mutuamente gerando a percepção que o indivíduo tem do seu ambiente (COSTA E COLESANTI, 2011).

$\mathrm{Na}$ presente pesquisa foram percebidos diversos sentimentos desenvolvidos durante a trilha, sendo em sua maioria, sensações de bem-estar. Na décima sexta estação foi possível perceber as sensações finais, da última estação de parada. Foram evidentes as sensações de cansaço físico, tendo em vista que a trilha totalizou 2,2 mil metros, mas também a de prazer e bem-estar, "Ah, como é bom sentar", "Tô cansado mas foi legal", "Caminhar dá fome”, "Eu amo piquenique", "Prof, podemos voltar mais vezes?", "Traz a gente de novo?”, "Quando vamos vir de novo?".

Os relatos dos estudantes reforçam que a última estação deve ser um momento destinado para além do fechamento do roteiro, sendo ideal para um piquenique coletivo onde todos possam se hidratar, descansar e aproveitar o bom convívio para um delicioso lanche partilhado.

\subsection{DADOS DO QUESTIONÁRIO PÓS-AULA DE CAMPO}

No questionário pós-aula de campo, os estudantes foram perguntados sobre o que acharam de mais interessante durante a aula. As respostas foram categorizadas de acordo com a semelhança de citações, sendo o grupo mais representativo o dos animais, seguido das árvores e das explicações da pesquisadora nos pontos de parada.

A segunda e a terceira pergunta do questionário pós-aula de campo investigou o que os estudantes mais gostaram e menos gostaram durante a aula de campo. Dentre os aspectos que mais gostaram, a categoria aprendizado foi citada oito $(\mathrm{N}=08)$ vezes, o contato com a natureza apareceu com cinco $(\mathrm{N}=05)$ citações. As categorias animais e piquenique tiveram duas citações cada $(\mathrm{N}=02)$. Um estudante citou a caminhada com os amigos como o que mais gostou e outro respondeu que gostou de tudo, sem citar ou descrever um momento em específico.

As manifestações afetivas, de empatia ficaram evidentes durante a realização da aula. Tais indícios são corroborados por Junqueira e Oliveira (2015) que estudam a relação entre as aulas de campo e Educação Ambiental e as Potencialidades Formativas. As autoras relatam que propor atividades interdisciplinares durante as aulas de campo possibilita maior número de laços afetivos entre colegas.

Nos aspectos que menos gostaram houve maior diversidade nas respostas. Como pontos negativos, a presença de mosquitos foi citada três vezes $(\mathrm{N}=03)$, o cansaço em percorrer toda a 
trilha, a conversa em alguns momentos e pouco tempo de duração da aula, foram citadas duas vezes $(\mathrm{N}=02)$ cada. As demais respostas foram citadas apenas uma vez cada, sendo eles, medo de lagartos e ausência de animais. Quando perguntados se gostaram de ter participado da aula de campo, todos os estudantes responderam que sim. A mesma situação de respostas ocorreu ao serem perguntados se gostariam que seus professores realizassem mais aulas de campo.

Quando questionados o porquê gostariam de mais aulas de campo, as categorias necessidade de aulas diversificadas e união entre teoria e prática apareceram com cinco citações cada $(\mathrm{N}=05)$. Aulas de campo como facilitador do aprendizado foi citada duas vezes $(\mathrm{N}=02)$. Aspectos como distração, lazer e diversão apareceram uma vez cada. Um estudante não respondeu a parte discursiva da questão.

Seniciato e Cavassan (2008) partem de um novo olhar para as aulas em ambientes naturais. Através da observação e análise de uma aula de campo com estudantes do ensino fundamental, os autores discorrem sua argumentação enfatizando que o interesse e a motivação são mais frequentes nas aulas desenvolvidas em ambientes naturais quando comparadas às aulas expositivas tradicionais, isso porque os componentes afetivos se fazem presentes nesse tipo de prática.

O último item do questionário pós-aula de campo foi um quadro com afirmações baseadas nas concepções de Sauvé (2005) onde os estudantes foram convidados a marcar o grau de concordância para cada sentença, assim, deveriam marcar se concordavam, eram neutros ou discordavam das afirmações. Foi esclarecido aos estudantes que não havia respostas certas ou erradas, o objetivo era identificar as Concepções.

De acordo com os resultados do grau de concordância dos estudantes, percebeu-se concepções mais abrangentes sobre o ambiente se comparado aos resultados obtidos durante a roda de conversa, momento em que foi possível perceber o alto grau de discordância dos estudantes em Concepções como Projeto Comunitário, Biosfera e Sistema, sendo fortemente marcada as Concepções Natureza e Lugar em que se vive.

No questionário pós-aula de campo percebeu-se as mudanças de Concepções dos estudantes, o que confirma a hipótese de que a Educação Ambiental na Educação Básica é uma alternativa possível por meio da inserção de Aula de Campo.

Os dados revelaram que a Concepção inicial dos estudantes participantes da pesquisa era em grande parte naturalista e pode ser justificado pelo forte enraizamento dessa concepção durante toda a vida escolar do estudante. 
Isso é percebido ao analisar o dado e correlacioná-lo com situações que possivelmente ainda acontecem nas escolas, como por exemplo, as comemorações no Dia Internacional do Meio Ambiente onde é solicitado aos estudantes para que plantem uma muda de árvore, façam artesanato utilizando garrafas pet ou enfeitem um cartaz no intuito de simbolizar ações ambientais.

É necessário ir além, os estudantes precisam ser convidados a reflexão, (re) pensando que toda ação tem uma consequência e que somente o próprio sujeito é quem decide se estas serão positivas ou negativas.

Os jovens têm grande potencial para transformação do meio, precisam apenas de mediação. Neste sentido, Anastasiou (2004) corrobora quando utiliza a expressão "ensinar com sabor". Um estudante quando convidado a reflexão por um professor que o ensina com sabor poderá com maior facilidade, desenvolver pensamentos críticos de suas ações. As reflexões mediadas pelo professor devem ser pautadas na ética para que não se formem jovens culpabilizadores, porque antes de serem capazes de apontar culpados é preciso que se sintam pertencentes à sociedade, para só então, pensar em ações que caminhem para a construção de uma sociedade sustentável, justa e fraterna.

\section{CONSIDERAÇões FINAIS}

A Educação Ambiental trabalhada durante a Aula de Campo foi uma importante aliada na construção de reflexões e conceitos amplos e interdisciplinares no que tange os conteúdos basilares, mostrando ser uma alternativa possível não só para diminuir o reducionismo e a fragmentação conceitual, mas também para despertar o estudante para o conhecimento, possibilitando o desenvolvimento de um jovem autônomo, solidário e competente.

Retomando os dados, foi possível identificar que antes da vivência em campo os estudantes não tinham clareza do que entendem por Educação Ambiental e seus desdobramentos. As concepções posteriores apontam abrangência conceitual e apesar da Concepção Natureza permanecer entre as mais citadas, os dados revelam maior amplitude de concepções pós-aula de campo se comparado aos resultados do questionário pré-aula de campo e da roda de conversa.

Vale salientar que a Concepção "Natureza" não deve ser vista com menor importância. Emocionar-se pelo belo, encantar-se pela natureza é um forte indício de que somos responsáveis por nossas ações. O encantamento pode ser o início de lutas pelo bem comum, pelo lugar em 
que se vive, pela busca para resolução de problemas, pelo gerenciamento de recursos, por projetos comunitários, pela biosfera e pela compreensão do sistema.

A partir dos dados dos questionários e dos relatos pode-se concluir que durante a aula de campo, fluíram sentimentos de amizade, solidariedade, partilha e respeito, que desencadearam em aprendizados significativos dos conceitos científicos através da vivência em ambiente natural. Propõe-se dar continuidade a pesquisas com esse teor, para que pesquisas sejam mais do que dados estatísticos, sejam dados oriundos de vivência coletiva, do aprendizado mútuo.

\section{REFERÊNCIAS}

ANASTASIOU, L. G. C.; ALVES, L. P. (Orgs.). Processos de Ensinagem na Universidade. Pressupostos para as estratégias de trabalho em aula. 3.ed. Joinville: Editora Univalle, 2004. 145 p.

ANASTASIOU, L. G. C. Ensinar, Aprender, Apreender e Processos de Ensinagem. In: ANASTASIOU, L. G. C.; ALVES, L. P. (Orgs.). Processos de Ensinagem na Universidade. Pressupostos para as estratégias de trabalho em aula. 3.ed. Joinville: Editora Univalle, 2004. 145 p.

BARROS, M.P.; MUSIS, C.R.; HORNICK, C. Parque da Cidade Mãe Bonifácia, Cuiabá-MT: Topofilia e amenização climática em um fragmento de cerrado urbano. Revista da Sociedade Brasileira de Arborização Urbana, v.5, n.2, p.01-18, 2010.

BRASIL. Lei no 9.795, de 27 de abril de 1999. Institui a Política Nacional de Educação Ambiental e dá outras providências. Diário Oficial da União, Brasília, 1999.

BRASIL. Lei no 13.005, de 25 junho de 2014. Aprova o Plano Nacional de Educação - PNE 2014 - 2024 e dá outras providências. Diário Oficial da União, Brasília, 2014.

BRASIL. Portaria $\mathrm{N}^{\circ}-1.145$, de 10 de Outubro de 2016. Institui o Programa de Fomento à Implementação de Escolas em Tempo Integral. Diário Oficial da União, Brasília, 2016. http://portal.mec.gov.br/docman/outubro-2016-pdf/49121-port-1145-11out-pdf/file acessado em $20 / 08 / 2018$.

BRASIL. Medida Provisória no 746, de 22 de setembro de 2016. Diário Oficial da União, Edição Extra. Brasília, 2016. Disponível em http://portal.mec.gov.br/index.php?option=com_docman\&view=download\&alias=48601-mp746-ensino-medio-link-pdf\&category_slug=setembro-2016-pdf\&Itemid=30192 acessado em 20/08/2018.

CÉSAR, D. M.; CAMPOS, C. R. P. Percepções ambientais em uma aula de campo no Ensino de Ciências: o que dizem os estudantes. In: XI Encontro Nacional de Pesquisa em Educação em Ciências, 2017. Anais. Florianópolis: Universidade Federal de Santa Catarina. n.p.2017.

COSTA, R.G.S.; COLESANTI, M.M.A Contribuição da Percepção Ambiental nos Estudos das Áreas Verdes. RAEGA v. 22, p. 238-251, 2011. 
JUNQUEIRA, M.E.R.; OLIVEIRA, S.S. de. Aulas de Campo e Educação Ambiental: Potencialidades Formativas e Contribuições para o Desenvolvimento Local Sustentável. Revista brasileira de Educação Ambiental. v.10, n 3, p.111-123, 2015.

MATO GROSSO. Lei Complementar $\mathbf{N}^{\circ}$ 043, de 28 de Dezembro de 2006. Plano Diretor Participativo de Desenvolvimento Urbano e Ambiental do Município de Rondonópolis, e dá outras providências. Disponível em

http://www.rondonopolis.mt.gov.br/docs/Lei_Complementar_043-28-12-2006PLANO_DIRETOR.pdf acessado em 20/11/2017.

MATO GROSSO. Lei $\mathbf{N}^{\mathbf{0}} \mathbf{1 0 . 1 1 1}$, de 06 de Junho de 2014. Dispõe sobre a revisão e alteração do Plano Estadual de Educação, instituído pela Lei $n^{\circ}$ 8.806, de 10 de janeiro de 2008. Disponível em http://fne.mec.gov.br/images/PEE/MTPEE.pdf acessado em: 20/11/2017

MATO GROSSO. PEE - Plano Estadual de Educação. Secretaria de Estado de Educação. Cuiabá: 2006.

ORÓ, I. Conhecimento do Meio Natural. In: ZABALA, A. Como trabalhar os conteúdos procedimentais em aula. $2^{a}$ ed. Porto Alegre: Editora Artmed, 1999. 194p. cap.1 p. 21-32.

SAUVÉ, L. Educação Ambiental: limites e possibilidades. Educação e Pesquisa. v.31 n.2, p.317-332. 2005.

SENICIATO, T.; CAVASSAN. O. Afetividade, motivação e construção de conhecimento científico nas aulas desenvolvidas em ambientes naturais. Ciências e Cognição, v.13, n.3, p.120-136. 2008.

Recebido em:25 de julho de 2018. Aprovado em: 28 de agosto de 2018. 